\title{
Are cancer care pathways associated with longer waiting times. Analysing crowding out effects in radiology, pathology, and surgery
}

Olle Olsson

The self-archived postprint version of this journal article is available at Linköping University Institutional Repository (DiVA):

http://urn.kb.se/resolve?urn=urn:nbn:se:liu:diva-172366

N.B.: When citing this work, cite the original publication.

Olsson, O., (2020), Are cancer care pathways associated with longer waiting times. Analysing crowding out effects in radiology, pathology, and surgery, International Journal of Care Coordination, , 2053434520978173. https://doi.org/10.1177/2053434520978173

Original publication available at:

https://doi.org/10.1177/2053434520978173

Copyright: SAGE PUBLICATIONS LTD

https://uk.sagepub.com/ 


\section{Are cancer care pathways associated with longer waiting times. Analysing crowding out effects in radiology, pathology, and surgery}

\section{Abstract}

\section{Introduction}

In 2015, Sweden initiated the implementation of standardised cancer care pathways (CCPs). With short, nationally imposed target times from diagnosis to first treatment, the issue of crowding out effects has been debated. This study investigate whether the implementation of CCPs is associated with longer waiting times for surgery, radiology scans and pathology analyses for other patient groups.

\section{Methods}

Data from the internal computer systems used in radiology, pathology and surgery to plan and follow the production at a county hospital in Sweden during 2014-2017 were analysed. By utilising the different priority categories used in these specialties, changes in waiting times before and after the implementation of CCPs could be analysed.

\section{Results}

The results are consistent with an association between the implementation of CCPs and longer waiting times for the priority category prioritised immediately after the CCP category in all specialties. In addition, none of the lowest priority categories within each subspecialty have experienced increased waiting times after CCP implementation.

\section{Discussion}

These results are consistent with a change in prioritisation where CCP patients are receiving shorter waiting times after CCP implementation at the expense of other patient groups. Crowding out effects related to CCP implementation have not been previously researched. This study therefore fills a gap in present literature. With an increased awareness of these challenges, and a more holistic perspective in the implementation process, actions can be put in place to identify and counteract crowding out effects.

\section{Introduction}

The second most common cause of death in Sweden is cancer. ${ }^{1}$ In recent years, national initiatives have been introduced to achieve improved, more available, and secure cancer treatment and care. One of these initiatives involves the introduction of standardised cancer care pathways (CCPs), a fouryear programme initiated in $2015 .^{2}$ The CCP programme is a model that originates from the Danish example of Pakkeforløb. This was initiated due to the lower cancer survival rates in Denmark in comparison to the other Nordic and many European countries. ${ }^{3,4}$ Studies have also indicated that part of the reason for this was that Danish cancer patients seemed to have progressed further along in the stages of disease than patients in the other Nordic countries by the time treatment was initiated. ${ }^{5,6}$ The CCP model focuses on the initial diagnostic phase, beginning with the concept of well-founded suspicion of a specific cancer diagnosis, and ends with the start of first treatment. A well-founded suspicion requires that a set of alarm symptoms and results of previous tests is met. The CCP guidelines also describe the activities and tests that need to be performed in the cancer investigation. The CCP guidelines also followed the criteria for being identified as a clinical pathway developed by Kinsman et al. ${ }^{7}$ For each cancer diagnosis, the target time for the total number of days from well-founded suspicion to start of first treatment is described and followed nationally. 
In Sweden, the CCP programme was initiated by the Swedish government (Ministry of Health and Social Affairs). The Swedish healthcare system is comprised of 21 independent regions that provide primary and secondary levels of care. The CCP programme includes incentives to implement the reform based on a national performance-based reward grant of approximately 200 million euro. Overall, more than 30 cancer diagnoses are covered in the programme, with the implementation being initiated in a stepwise manner between 2015 and 2017.

In a systematic review of randomised controlled trials, care pathways for predictable trajectories of care can be effective in ensuring that patients receive relevant clinical interventions and assessments in a timely manner. ${ }^{8}$ However, care pathway implementation also comprises a dual complexity, where the care pathway itself represents a complex intervention, while the organisational context upon which the care pathway is being implemented is also a complex system. ${ }^{9}$ Acknowledging this twofold complexity includes careful consideration of the interactions between the intervention and the context. ${ }^{10}$ One of these concerns upon CCP implementation in Sweden has been crowding out effects. Different actors have interpreted crowding out effects differently. ${ }^{11}$ However, in a Swedish government bill of 2009, crowding out is defined as "situations when patients with lower priority are provided treatment or care before patients with higher priority (thus a larger medical need)" (author's translation). ${ }^{12, p .40}$ The issue of crowding out has been debated in the media; for example, with claims concerning longer waiting times for urological surgery and radiology exams caused by the introduction of CCPs. ${ }^{13,14,15}$ Possible crowding out effects due to the implementation of CCPs have been subdivided by the National Board of Health and Welfare: ${ }^{11}$

1. Crowding out of other parts of the patient pathway;

2. Crowding out of the same patient group as well as those who do not fit/can manage/want to follow the CCP;

3. Crowding out of other investigations, treatments and care, both within the same and other disease areas.

Schmidt et al. ${ }^{16}$ have identified that diagnostic procedures with limited resources and a shortage of specialists can lead to crowding out effects of both the second and third types described above, especially if the CCPs increase the risk of unnecessary examinations being carried out. Smeds and Poksinska ${ }^{17}$ have also identified three possible crowding out effects following CCP implementation. The push out effect matches the third type described above, while the second type is divided into an exclusion effect and an inclusion effect, in which the latter corresponds to the effect where more patients from vulnerable groups are diagnosed and treated for cancer.

In Denmark, waiting times have been reduced for most cancer areas following the implementation of CCPs. ${ }^{18,19}$ However, crowding out effects have not been explicitly addressed. When introducing twoweek-wait clinics for cancer diagnostics in the United Kingdom, waiting times for patient groups at low risk or having vague symptoms of cancer have been negatively influenced in favour of high-risk groups. ${ }^{20}$ For breast cancer, there is also evidence of longer waiting times for routine referrals when introducing the two-week-wait for urgent referrals. ${ }^{21,22}$ This was probably due to crowding out effects from the two-week-wait group.

In a progress report concerning the implementation of CCPs in Sweden, support functions regarding diagnostics and treatment, namely pathology, radiology and surgery, are those where crowding out effects are considered most likely. ${ }^{11}$ The report also states that one reason for this is that it is common for there to be a lack of capacity in these specialties. Since these specialties are involved in diagnostics and treatment in many CCPs, volumes can become large. They are therefore studied in this research. Since these specialties are studied, a consequence is that it is the waiting times for surgery, pathology 
analyses and radiology scans that will be analysed. In terms of the division of different types of crowding out effects previously discussed, it comprises the third type. Due to these methodological choices, the analyses are not limited to analysing waiting times for patients with higher priority than the patients in the CCPs; instead, patients with lower, equal and higher priority in comparison to those in the CCPs are included, since longer waiting times for all of these groups are of interest and have been identified in previous research for other interventions..$^{20,21,22}$ Since previous research in Denmark has also shown that waiting times have been shortened for cancer patients after introducing CCPs ${ }^{18,19}$, the purpose of this study is:

To investigate whether the implementation of CCPs is associated with longer waiting times for surgery, radiology scans and pathology analyses for other patient groups.

The term "other patient groups" represents the patients receiving and waiting for surgery, radiology scans and pathology analyses from the same healthcare resources that perform these services for the CCP patients. In the section below, this subject is further described.

\section{Methods}

\section{Study design and population}

In this study, data from the internal computer systems used by the specialties to plan and follow their production at Kalmar County Hospital, the largest hospital in a small county in southern Sweden with 240000 inhabitants, were analysed. In the specialties of pathology, radiology and surgery, many different analyses, scans and surgical procedures are performed and the possible crowding out effects of implementing CCPs are influenced by the organisation and processes surrounding these. Crowding out effects are more relevant to study if the quantity of CCP-related analyses/scans/surgical procedures is large in relation to the total number of analyses/scans/surgical procedures. For example, shorter waiting times for CCP analyses that comprise $50 \%$ of the total number of analyses have a greater potential to cause crowding out effects when implementing CCPs than if the CCP analyses comprised only $1 \%$ of the total number. These considerations have guided the choice of analyses/scans/surgical procedures to study for crowding out effects.

Some operating theatres are used for elective surgery and some for acute surgery at the hospital. The operating theatres are further subdivided so that each subspecialty is assigned a number of operating theatres on different weekdays. The largest number of diagnosed cancer types, which are also operated upon in Kalmar, are prostate cancer, cancer of the bladder and upper urinary tract, breast cancer and colorectal cancer. These are operated upon by the urology subspecialty, breast subspecialty and lower gastrointestinal (LGI) subspecialty, respectively. Due to the division of operating theatre space, crowding out effects are not studied among other subspecialties or acute surgeries, but only within the subspecialties studied. Within pathology, it is cytopathology and histopathology that are the areas where the proportion of analyses from CCPs are expected to be the highest. These are also an alternative during the diagnostics phase in most CCPs. Therefore, they are included in the study. The same line of argument is applicable for magnetic resonance imaging (MRI) and computed tomography (CT) scans in the radiology specialty; hence, these are also analysed in the study.

\section{Data collection}

In analysing crowding out effects, it is the waiting times between registration and completion of a surgery/radiology scan/pathology analysis that are studied. For surgical procedures, this corresponds to the date when doctor and patient jointly decide upon surgery until the date when the surgical procedure is performed. In radiology, it is the waiting time between the acceptance of an electronic referral up to the time when a radiologist has sent the final referral response. Lastly, in pathology, it 
corresponds to the waiting time from arrival of the referral until a pathologist has sent the final referral response.

Within all of the studied specialties, a priority category is decided when registering a surgery/scan/analysis. This priority is decided by a doctor and is the basis for deciding how quickly a surgery/scan/analysis should be completed. These priority categories are used in the analysis of how changes in waiting times are associated with CCP implementation. For all specialties, CCP became a new priority category after the implementation. In the surgical specialty, three priority categories are also used for elective surgery, with different waiting time targets. In radiology, there are five different priority categories that correspond to different waiting time targets. The first two are radiology scans performed on acute patients and inpatients. The radiology department has two CT scanners and two MRIs. The radiology scans in the first two priority categories are performed on one of these machines, although not exclusively. Therefore, none of these five priority categories are excluded from the analysis. In addition to these priority categories, there are different types of priority categories for controls that are performed during a specific timeframe. Since the waiting times for these scans are delimited, they are excluded. In addition, special priority categories with small volumes and radiology scans lacking priority categories are excluded.

In the pathology specialty, two priority categories are used for pathology analyses, with different waiting time targets. In addition, there are several special priority categories with very small volumes compared to the previously mentioned two. These are thus excluded from the analysis. Below, in Table 1 , a summary of all surgeries/radiology scans/pathology analyses, and the division of these among the priority categories, is provided. For the radiology specialty, the number of scans that are controls and those that are lacking a priority category are also specified.

Table 1 - Number of surgeries/scans/analyses within each priority category

\begin{tabular}{|c|c|c|c|c|c|c|c|}
\hline & \multicolumn{2}{|c|}{ Pathology } & \multicolumn{2}{|c|}{ Radiology } & \multicolumn{3}{|c|}{ Surgery } \\
\hline & Histopathology & Cytopathology & CT scans & MRI scans & Urology & Breast & LGI \\
\hline Included & 48813 & 10359 & 35841 & 12635 & 1514 & 794 & 763 \\
\hline $\mathrm{CCP}$ & 2734 & 812 & 1207 & 105 & 102 & 85 & 89 \\
\hline Prio_1 & 3417 & 860 & 21256 & 1266 & 567 & 73 & 96 \\
\hline Prio_2 & 42662 & 8687 & 5707 & 2806 & 617 & 537 & 383 \\
\hline Prio_3 & - & - & 3687 & 2129 & 228 & 99 & 195 \\
\hline Prio_4 & - & - & 2977 & 4016 & - & - & - \\
\hline Prio_5 & - & - & 1007 & 2313 & - & - & - \\
\hline Excluded & 2053 & 512 & 15498 & 5522 & 0 & 0 & 0 \\
\hline Controls & - & - & 13773 & 3883 & - & - & - \\
\hline Lacking priority & - & - & 1061 & 989 & - & - & - \\
\hline
\end{tabular}

Before CCP implementation two priority categories were used in pathology, five in radiology and three for surgeries. Each of these priority categories have a waiting time target. Among the excluded priority categories are several special priority categories with very small volumes (pathology and radiology) as well as controls that are performed during a specific timeframe and those lacking a priority category (radiology).

Data were collected from the internal computer systems used by the specialties to plan and follow their production. Data have been validated by plotting inflow, production and waiting times for the studied data and thereafter presenting and discussing it with representatives working within the specialties. Changes influencing the number of surgeries/radiology scans/pathology analyses produced or registered were also discussed with the representatives. No changes having a major influence on these parameters were identified. 


\section{Data analysis}

To investigate whether the implementation of CCPs is causing crowding out effects, waiting times before and after the implementation were analysed. For pathology and radiology, a middle period was also defined. The reason is that the CCPs for the most common cancer types were implemented on different dates during a period of one year, from September 2015 to September 2016. The volumes of radiology scans and pathology analyses thus increased continually during this period. For exact dates of the border between the studied periods, see Table 2 .

Table 2 - Start and end dates, as well as the number of days for the before, middle and after period for each subspecialty.

\begin{tabular}{|c|c|c|c|c|c|c|c|c|c|}
\cline { 2 - 11 } \multicolumn{1}{c|}{} & \multicolumn{3}{c|}{ Before } & \multicolumn{3}{c|}{ Middle } & \multicolumn{3}{c|}{ After } \\
\hline Subspecialty & Start & End & Days & Start & End & Days & Start & End & Days \\
\hline Histopathology & $2015-01-01$ & $2015-09-04$ & 246 & $2015-09-05$ & $2016-10-17$ & 408 & $2016-10-18$ & $2017-08-31$ & 317 \\
\hline Cytopathology & $2015-01-01$ & $2015-09-22$ & 264 & $2015-09-23$ & $2016-10-17$ & 390 & $2016-10-18$ & $2017-08-31$ & 317 \\
\hline CT scans & $2015-01-01$ & $2015-09-17$ & 259 & $2015-09-18$ & $2016-10-17$ & 395 & $2016-10-18$ & $2017-08-31$ & 317 \\
\hline MRI scans & $2015-01-01$ & $2015-09-01$ & 243 & $2015-09-02$ & $2016-10-17$ & 411 & $2016-10-18$ & $2017-08-31$ & 317 \\
\hline Urology & $2014-09-01$ & $2015-09-03$ & 367 & N/A & N/A & N/A & $2015-09-04$ & $2017-06-20$ & 655 \\
Breast & $2014-09-01$ & $2016-10-17$ & 777 & N/A & N/A & N/A & $2016-10-18$ & $2017-09-29$ & 346 \\
\hline LGI & $2014-09-01$ & $2016-04-18$ & 595 & N/A & N/A & N/A & $2016-04-19$ & $2017-06-20$ & 427 \\
\hline
\end{tabular}

For the surgical subspecialties (Urology, Breast, LGI) the after period begins directly after the before period ends. Hence, there are no middle period (non-applicable).

The collected data includes all surgeries/radiology scans/pathology analyses performed between the start date of the before period and the end date of the after period (see Table 2 for exact dates). For each surgery/radiology scan/pathology analysis the following information were collected:

- Date and time for registration of surgery/radiology scan/pathology analysis

- Date and time for completion of surgery/radiology scan/pathology analysis

- Specialty

- Subspecialty

- Priority category

Since no personal data, such as social security number were collected, and thus no individual or their personal information could be extracted, there was no need to apply for an ethical approval of this study under the Swedish legislation.

The date for the completion of surgery/radiology scan/pathology analysis are used to allot a surgery/scan/analysis to a period. The gathered data are stored in Excel format and was analysed using the Statistica 12 software.

To structure the analysis of the collected data the purpose of this study, "To investigate whether the implementation of CCPs is associated with longer waiting times for surgery, radiology scans and pathology analyses for other patient groups", has been divided into three research questions. These are:

RQ1: Are there patterns in the changes in waiting times for the specialties and subspecialties that are associated with the implementation of CCPS

RQ2: Are there patterns in the changes in waiting times for the different priority categories that are associated with the implementation of CCPS 
RQ3: Are there patterns in how the changes in waiting times develop over time that are associated with the implementation of CCPS

The analysis focuses on identifying patterns between the specialties, subspecialties and priority categories that are associated with CCP implementation. To identify differences in waiting times between the before, middle and after period, mean and median values are included. To further analyse the difference between the before and after period the $p$-value from the non-parametric MannWhitney $U$ test is calculated, testing the null hypothesis that the waiting times in these periods are equal. In this study, multiple tests are used. The sample sizes are also rather large. Hence, an alpha level of .05 or .01 could provide statistical significance for small changes for most of the tests in this study, where many of these changes however lack a practical relevance, and are difficult to assess. The alpha level is therefore adjusted downward, as suggested by some researchers ${ }^{23,24}$ to .001 . In addition to the median value for the before and after period, the first and third quartile is also calculated to provide a range. By analysing the first and third quartile, in addition to the $p$-value the results becomes more robust, in line with recommendation from statisticians when analysing large samples. ${ }^{25}$ Since the inflow and production of surgeries/radiology scans/pathology analyses also influence waiting times, changes in these parameters between the before and after period are also included when analysing the research questions.

\section{Results}

In Table 3, descriptive statistics for the before and after period are presented. For the middle period, data are provided in Appendix 1. To condense the information in Table 3, the following text summarises the changes in waiting times between the before and after period as well as changes in inflow and production between the two periods for the subspecialties. The proportion of CCP analyses/scans/surgeries of total volume in the after period is also included in the text.

Table 3 - Descriptive statistics for the before and after period

\begin{tabular}{|c|c|c|c|c|c|c|c|c|c|c|c|}
\hline & & \multicolumn{4}{|c|}{ Before } & \multicolumn{5}{|c|}{ After } & \multirow[b]{2}{*}{$\begin{array}{c}\text { p-value } \\
\text { (MW) }\end{array}$} \\
\hline \multicolumn{2}{|c|}{ Speciality } & Number & Mean (SD) & $\begin{array}{c}\text { Median (Q1- } \\
\text { Q3) }\end{array}$ & $\begin{array}{c}\text { Prod. } \\
\text { /month }\end{array}$ & Number & Mean (SD) & $\begin{array}{c}\text { Median (Q1- } \\
\text { Q3) }\end{array}$ & $\begin{array}{l}\text { +/- Prod. } \\
\text { /month }\end{array}$ & $\begin{array}{c}+/- \\
\text { Inflow } \\
\text { /month }\end{array}$ & \\
\hline \multicolumn{2}{|c|}{ Pathology } & & & & & & & & & & \\
\hline \multirow[t]{3}{*}{ Cyto } & Prio1 & 339 & $2.75(2.49)$ & $2.1(1.1-3.9)$ & 40 & 158 & $2.13(1.77)$ & $1.7(1.0-2.9)$ & -25 & -25 & $<0.001$ \\
\hline & CCP & - & & & & 508 & $2.84(2.28)$ & $2.1(1.1-4.1)$ & 48 & 47 & - \\
\hline & Prio2 & 2597 & $4.35(3.58)$ & $3.9(1.9-5.9)$ & 305 & 2492 & $3.71(3.64)$ & $3.0(1.1-5.0)$ & -72 & -79 & $<0.001$ \\
\hline \multirow[t]{3}{*}{ Histo } & CCP & - & & & & 1942 & $5.64(3.18)$ & $5.1(3.2-7.0)$ & 178 & 175 & \\
\hline & Prio1 & 1203 & $5.73(4.11)$ & $4.9(2.3-7.2)$ & 152 & 666 & $6.06(4.00)$ & $5.3(3.2-7.1)$ & -89 & -93 & $<0.001$ \\
\hline & Prio2 & 10982 & $11.89(4.14)$ & $12.0(9.0-14.0)$ & 1410 & 13302 & $10.81(4.81)$ & $10.1(7.2-13.1)$ & -274 & -379 & $<0.001$ \\
\hline \multicolumn{12}{|c|}{ Radiology } \\
\hline \multirow[t]{6}{*}{ CT } & Prio1 & 4667 & $3.60(6.61)$ & $1.7(0.6-4.1)$ & 551 & 8145 & $3.75(7.22)$ & $1.6(0.7-3.9)$ & -33 & -54 & 0.031 \\
\hline & Prio2 & 1766 & $5.61(8.45)$ & $3.0(1.0-7.0)$ & 209 & 1693 & $6.15(8.69)$ & 3.7 (1.2-7.9) & -101 & -109 & $<0.001$ \\
\hline & CCP & - & & & & 721 & $9.97(7.52)$ & $7.9(5.4-12.0)$ & 67 & 65 & \\
\hline & Prio3 & 754 & $14.81(10.85)$ & $13.0(8.2-18.2)$ & 89 & 1251 & $17.35(11.24)$ & $15.3(12-21)$ & 23 & 19 & $<0.001$ \\
\hline & Prio4 & 806 & $51.94(26.45)$ & $49.6(32-67)$ & 97 & 731 & $47.32(30.06)$ & $39.1(28-56)$ & -48 & -46 & $<0.001$ \\
\hline & Prio5 & 242 & 73.54 (32.35) & 73.6 (49-97) & 29 & 261 & $51.67(25.20)$ & $44.9(34-64)$ & -5.0 & -2.8 & $<0.001$ \\
\hline \multirow[t]{3}{*}{ MRI } & Prio1 & 297 & $5.78(8.01)$ & $3.8(1.1-7.2)$ & 38 & 407 & $7.50(7.40)$ & $5.1(2.1-10.9)$ & -0.9 & -5.8 & $<0.001$ \\
\hline & Prio2 & 585 & $6.80(6.87)$ & $5.0(2.3-8.0)$ & 75 & 1009 & $6.59(6.73)$ & 4.1 (1.9-9.1) & 18 & 8.8 & 0.107 \\
\hline & CCP & - & & & & 74 & $13.49(13.75)$ & $9.2(7.1-13.2)$ & 7.5 & 7.4 & \\
\hline
\end{tabular}




\begin{tabular}{|c|c|c|c|c|c|c|c|c|c|c|c|}
\hline & Prio3 & 511 & $18.34(17.23)$ & $15.0(11-20)$ & 66 & 755 & $17.55(11.20)$ & $15.0(11-22)$ & 3.2 & -1.0 & 0.765 \\
\hline & Prio4 & 917 & $59.73(35.62)$ & $55.5(37-73)$ & 118 & 1298 & $66.90(38.01)$ & $59.2(44-84)$ & 0.7 & 0.0 & $<0.001$ \\
\hline & Prio5 & 776 & $90.62(41.50)$ & $90.2(66-112)$ & 100 & 623 & $90.88(49.15)$ & $87.2(66-110)$ & -42 & -25 & 0.467 \\
\hline Surgery & & & & & & & & & & & \\
Breast & Prio1 & 47 & $13.57(15.28)$ & $10.0(4.0-19.0)$ & 1.9 & 26 & $15.19(10.28)$ & $11.0(8.0-27)$ & 0.6 & 0.5 & 0.211 \\
& CCP & - & & & & 84 & $17.33(11.22)$ & $15.0(8.0-21.0)$ & 7.6 & 7.6 & \\
\hline & Prio2 & 438 & $20.73(16.78)$ & $16.0(13-23)$ & 17 & 99 & $19.57(13.95)$ & $16.0(9.0-26.0)$ & -8.5 & -8.1 & 0.191 \\
\hline & Prio3 & 79 & $75.71(63.15)$ & $56.0(35-92)$ & 3.2 & 20 & $63.45(56.60)$ & $56.5(19-80)$ & -1.3 & -1.6 & 0.379 \\
\hline \multirow{2}{*}{ LGI } & Prio1 & 62 & $11.92(10.50)$ & $9.0(4.0-15.0)$ & 3.3 & 34 & $11.44(9.28)$ & $8.5(6.0-15.0)$ & -0.4 & -0.3 & 0.918 \\
\hline & CCP & - & & & & 88 & $19.92(15.30)$ & $17.0(11-24)$ & 6.7 & 6.7 & \\
\hline & Prio2 & 245 & $28.48(29.44)$ & $20.0(14-32)$ & 13 & 138 & $38.12(54.94)$ & $28.0(18-38)$ & -2.6 & -3.4 & $<0.001$ \\
\hline & Prio3 & 120 & $106.78(95.49)$ & $79.0(52-132)$ & 6.5 & 75 & $101.1(82.85)$ & $76.0(47-138)$ & -1.1 & -1.9 & 0.911 \\
\hline Urology & Prio1 & 242 & $22.16(20.81)$ & $16.0(8.0-29.0)$ & 20 & 322 & $21.38(21.98)$ & $15.0(9.0-28)$ & -5.3 & -4.5 & 0.975 \\
\hline & CCP & - & & & & 101 & $26.03(15.26)$ & $24.0(13-36)$ & 4.9 & 4.9 & \\
\hline & Prio2 & 238 & $70.60(60.59)$ & $56.5(35-77)$ & 20 & 379 & $65.60(79.34)$ & $36.0(25-63)$ & -2.0 & -2.7 & $<0.001$ \\
\hline & Prio3 & 71 & $126.89(102.1)$ & $89.0(63-169)$ & 6.0 & 156 & $129.3(123.5)$ & $90.0(40-180)$ & 1.4 & 0.2 & 0.423 \\
\hline
\end{tabular}

Specialty: The specialty, subspecialty and priority category; Number: The number of surgeries/radiology scans/pathology analyses for each priority category and subspecialty produced in the before and after period respectively; Mean (SD): The mean value and standard deviation for the waiting times in number of days; Median (Q1-Q3): The median and first and third quartile for the waiting times in number of days; Prod./month: The production per month of surgeries/radiology scans/pathology analyses (calculated by dividing the number of surgeries/scans/analyses produced by the length of the period); +/- Prod./month: The change between the before and after period in the number of surgeries/radiology scans/pathology analyses produced; + - Inflow/month: The change between the before and after period in the number of surgeries/radiology scans/pathology analyses registered; $p$-value (MW): The $p$-value from the non-parametric Mann-Whitney $\mathrm{U}$ test. Since multiple test are used, only $p$-values at the level of 0.001 or below were accepted as significant. Significant $p$-values that represent prolonged waiting times are marked in bold.

In cytopathology, all priority categories have statistically significant $(p<0.001)$ decreases in waiting times in the after period. The inflow has also been $15 \%$ smaller and the CCP analyses comprised $16 \%$ of total numbers in the after period. For histopathology, waiting times were longer for first priority analyses while being shorter for second priority analyses in the after period, both statistically significant $(p<0.001)$. CCP analyses comprised $12 \%$ of total numbers in the after period and the inflow and production were both reduced by $20 \%$.

Waiting times for CT scans have changed, with second and third priority scans waiting longer and fourth and fifth priority scans waiting for shorter times during the after period compared to the before period. All changes statistically significant $(p<0.001)$. The inflow has been reduced by about $10 \%$ in the after period compared to the before period and CCP scans comprised $6 \%$ of total volume in the after period. For MRI scans, first priority and fourth priority scans have experienced statistically significant $(p<0.001)$ increases in waiting times in the after period. CCP analyses proportion were $2 \%$ in the after period.

There were no statistically significant $(p<0.001)$ changes in waiting times for breast surgery when comparing the before and after period. The proportion of CCP surgeries were $37 \%$ of the total volume. For LGI surgery, waiting times for second priority surgeries have a statistically significant $(p<0.001)$ increase in the after period with CCP surgeries comprising $26 \%$ of the total volume. Waiting times for surgery within the urology subspecialty have only changed with statistical significance $(p<0.001)$ for second priority surgeries, with shorter waiting times in the after period. CCP surgeries comprised $11 \%$ of the total volume of surgeries. 


\section{Discussion}

This section starts by addressing the three research questions stipulated in this study. It thereafter describes the main findings and relate these findings to previous research. It concludes by discussing the implications for patients, healthcare providers and policy makers.

When looking for patterns related to RQ1, it can be concluded that all specialties demonstrate both shorter and longer waiting times, and that the changes in waiting times among the subspecialties differed. Out of the seven subspecialties studied, two (histopathology and CT scans) have demonstrated both increasing and decreasing waiting times, two (cytopathology and urology surgery) only shorter waiting times, two only longer waiting times (MRI scans and LGI-surgery) and one had unchanged waiting times (breast surgery). At the same time, the proportion of analyses/scans/surgeries performed within CCPs have often been large enough to have potential effects on other priority categories during the after period. In the surgical specialty, the proportion of CCPs was $11-37 \%$ of the total volume in the subspecialty, in pathology the proportion was $12 \%$ and $16 \%$, while radiology demonstrated the smallest proportions, with $2 \%$ and $6 \%$ of total volume. MRI scans, with $2 \%$ CCP analyses, are most questionable concerning the possible measureable influence on waiting times for other priority categories.

Although the proportions of CCP analyses/scans/surgeries have a potential influence on waiting times, there are other factors that influence waiting times as well, an important one being the inflow, and another the production. For all subspecialties, the changes in inflow and production have been alike in both direction and magnitude. Within pathology, the inflow has been reduced, with $15 \%$ in cytopathology and $20 \%$ in histopathology, and these changes are likely to have shortened waiting times in the after period. In radiology, the inflow for MRI scans has been reduced by $10 \%$ in the after period compared with the before period, but despite this, waiting times have increased. For the other four subspecialties, inflow and production have been stable. Altogether, it does not seem that changes in inflow and production have been the only parameter associated with changes in waiting times for the different subspecialties. To summarize, there aren't any clear patterns between the implementation of CCPs and changes in waiting times when looking at RQ1.

There are two patterns identified when analysing RQ2. The first is that none of the lowest priority categories within each subspecialty have experienced increased waiting times in the after period.

For histopathology, CT scans and LGI surgery, the first priority category after CCP has also increased waiting times in the after period. These changes could be crowding out effects from the introduction of CCPs. Among the subspecialties that do not fit into this pattern, there could be plausible explanations:

- Cytopathology is the subspecialty with the largest reduction in inflow, $20 \%$, which could explain shorter waiting times.

- MRI has only a $2 \%$ proportion of CCP scans, making measurable crowding out effects unlikely.

- Breast surgery might not have shortened the waiting times for CCP surgery by much. By looking at the proportions of each priority category, it is likely that the patients who received a surgical procedure within CCP in the after period would have been prioritised to the second priority category if the procedure had been performed in the before period. Since the waiting times for these surgeries have not been reduced by very much, the potential crowding out effect is also small.

- In urology, there are two CCPs, and thus two different surgical procedures with different waiting time goals included. It is therefore less clear how changes in waiting times are associated with CCP implementation. 
Altogether, the results for the seven subspecialties are consistent with an association between the implementation of CCPs and longer waiting times for the priority category prioritised immediately after the CCP category.

RQ3 addresses how the changes in waiting times developed over time. In the middle period for histopathology (see Appendix 1), the CCP analyses had shorter waiting times, first priority analyses waiting times matched the before period and second priority waiting times matched the after period. The proportion of CCP analyses was also smaller. These patterns could indicate that it was only when the volume of CCP analyses became bigger that crowding out may have occurred.

Since some priority categories have shorter waiting times and some have longer waiting times for CT scans, it is possible that these changes are unrelated to the introduction of CCPs. The volume of CCP scans is approximately $6 \%$ of the total volume in the after period and the inflow has been reduced by about $10 \%$ compared to the before period. Waiting times were also reduced in the middle period for fourth and fifth priority scans and fairly maintained in the after period. Furthermore, the waiting times for third priority scans increased gradually, while waiting times for second priority scans increased during the middle period and thereafter slightly reduced. Since the proportion of CCP scans was smaller ( $3 \%$ compared to $6 \%$ ) during the middle period than the after period, it is possible that the increased waiting times for third priority scans are due to crowding out effects while the other changes were due to other events during the middle period.

For cytopathology and MRI scans, the changes in waiting times between the before and after period can have occurred over time, with waiting times in the middle period being between those in the before and after period. For the priority categories that didn't demonstrate statistically significant $(p<0.001)$ changes in waiting times between the before and after period the waiting times were practically the same in the middle period.

All in all, these patterns for how the waiting times developed between the before, middle and after period are consistent with the findings related to RQ2.

The presence of crowding out effects is dependent on reductions in waiting times for CCP analyses/scans/surgeries. Evidence of such reductions is difficult to demonstrate since it is difficult to establish which pathology analyses, radiology scans or surgical procedures would have been performed under a CCP in the before period. The exception is urology surgery, where these surgical procedures are easily identified, and the author, as operations developer at the hospital studied, has shown that waiting times have been reduced after introducing CCPs. There are also reasons to assume that surgeries, radiology scans and pathology analyses performed in CCPs have experienced shorter waiting times than they would have before the introduction of CCPs. In radiology, the CCP is the priority category with shortest waiting times after acute patients (Prio1) and inpatients (Prio2). Based on the changes in the proportions between the different priority categories for CT scans, the CCP category was likely previously prioritised mainly to the Prio4 category, thus receiving shorter waiting times after CCP implementation. In pathology the CCP priority category has the shortest waiting times in histopathology and second shortest in cytopathology. With decreased inflow in both Prio1 and Prio2 categories in cytopathology and histopathology in the after period it is difficult to assess how the CCP scans would have been prioritised in the before period. For surgeries, the changes in the proportions between the different priority categories point towards a majority of the CCP surgeries previously being categorised as Prio2, a category with longer waiting times than the CCP category in the after period. Previous research concerning the introductions of CCPs in Denmark has also shown that waiting times from referral to start of first treatment have decreased after the introduction of CCPs. ${ }^{18,19}$ 
Introducing CCPs has previously been shown to reduce waiting times for treatment ${ }^{18,19}$ and prioritising certain patient groups for cancer diagnostics increases waiting times for others. ${ }^{20,22}$ However, the presence and extent of crowding out effects when introducing CCPs and similar policy programmes have not been researched. The purpose of this study was therefore: "To investigate whether the implementation of CCPS is associated with longer waiting times for surgery, radiology scans and pathology analyses for other patient groups". The main findings of this study are related to RQ2. The results for the seven subspecialties are consistent with an association between the implementation of CCPs and longer waiting times for the priority category prioritised immediately after the CCP category. In addition, none of the lowest priority categories within each subspecialty have experienced increased waiting times after CCP implementation. This indicates that crowding out of low-priority patients is less probable. Both of these patterns are also consistent with a change in prioritisation where CCP patients are receiving shorter waiting times after CCP implementation. The priority category that are surpassed thus becomes downgraded, with longer waiting times as a result, while the least prioritised patients aren't affected, since the changes in prioritisation happen to patients already being prioritised before them. The patterns for how the waiting times developed over time, addressed in RQ3, are also consistent with the findings from the second research question.

Crowding out effects related to CCP implementation have not been previously researched. This study therefore fills a gap in present literature. The patterns identified can also be related to the crowding out effects identified when introducing the two-week-wait in United Kingdom, where waiting times for less prioritised patients increased. ${ }^{20,21,22}$ By separating the other patient groups in priority categories a more detailed understanding of potential crowding out effects is achieved, in addition to previous research. It further points to the need to consider of the interactions between the care pathway intervention and the context, discussed in previous research. ${ }^{10}$ To further deepen the understanding of these effects more quantitative research is needed to analyse the patterns identified in this study, and other potential crowding out effects, while also more qualitative research is needed to provide knowledge on how crowding out effects is formed and can be reduced in practice.

For healthcare providers and policy makers, this research provides insights into potential crowding out effects when introducing pathways and policy programs. With an increased awareness of these challenges a more holistic perspective can be used in the implementation process and actions can be put in place to identify and counteract crowding out effects. These issues are of importance to patients, for whom waiting times should be reasonable, and equitable based on medical needs.

\section{References}

1. National Board of Health and Welfare. Statistik om dödsorsaker, https://www.socialstyrelsen.se/statistik-och-data/statistik/statistikamnen/dodsorsaker/ (2019, accessed 8 July 2020).

2. Wilkens J, Thulesius H, Schmidt I, et al. The 2015 national cancer program in Sweden: introducing standardized care pathways in a decentralized system. Health Policy 2016; 12: 1378-1382.

3. Berrino F, De Angelis R, Sant M, et al. Survival for eight major cancers and all cancers combined for European adults diagnosed in 1995-99: results of the EUROCARE-4 study. Lancet Oncol 2007; 8: 773783.

4. Karim-Kos HE, De Vries E, Soerjomataram I, et al. Recent trends of cancer in Europe: A combined approach of incidence, survival and mortality for 17 cancer sites since the 1990s. Eur J Cancer 2008; 44: 1345-1389. 
5. Storm HH, Dickman PW, Engeland A, et al. Do morphology and stage explain the inferior lung cancer survival in Denmark?. Eur Respir J 1999; 13: 430-435.

6. Jensen AR, Garne JP, Storm HH, et al. Does stage at diagnosis explain the difference in survival after breast cancer in Denmark and Sweden?. Acta Oncol 2004; 43: 719-726.

7. Kinsman $L$, Rotter $T$, James $E$, et al. What is a clinical pathway? Development of a definition to inform the debate. BMC Med 2010; 8: 31.

8. Allen D, Gillen E, Rixson L. Systematic review of the effectiveness of integrated care pathways: what works, for whom, in which circumstances?. Int J Evid Based Healthc 2009; 7: 61-74.

9. Seys D, Panella M, VanZelm R, et al. Care pathways are complex interventions in complex systems: New European Pathway Association framework. Int J Care Coord 2019; 22: 5-9.

10. Shiell A, Hawe P and Gold L. Complex interventions or complex systems? Implications for health economic evaluation. BMJ 2008; 336: 1281-1283.

11. The National Board of Health and Welfare. Standardiserade vårdförlopp i cancervården Lägesrapport 2016, November 2016.

12. Ministry of Health and Social Affairs. Stärkt ställning för patienten - vårdgaranti, fast vårdkontakt och förnyad medicinsk bedömning. Governments bill 2009/10:67.

13. Lindström V. Överläkare varnar: "Ojämlik vård av godartad prostataförstoring undergräver kompetensnivån". Sjukhus/äkaren, 30 july 2018. https://www.sjukhuslakaren.se/overlakare-varnarojamlik-vard-av-godartat-prostataforstoring-underminerar-kompetensnivan/, Accessed 2019-04-30.

14. Åsgård S. Månader i röntgenkö på Akademiska. Dagens Medicin, 15 September 2017. https://www.dagensmedicin.se/artiklar/2017/09/15/mander-i-rontgenko-pa-akademiska/, Accessed 2019-04-30.

15. Lindström V. Verksamhetschefen håller med Sherif: "Det blev en undanträngningseffekt av SVF". Sjukhusläkaren, 10 August 2018. https://www.sjukhuslakaren.se/verksamhetschefen-haller-medsherif-det-blev-en-undantrangningseffekt-av-svf/, Accessed 2019-04-30.

16. Schmidt I, Thor J, Davidson T. The national program on standardized cancer care pathways in Sweden: Observations and findings half way through. Health Policy 2018; 122: 945-948.

17. Smeds M, Poksinska B. The effects of cancer care pathways on waiting times. Int J Qual Serv Sci 2019; 11: 204-216.

18. Probst HB, Andersen O. Cancer patient pathways in Denmark as a joint effort between bureaucrats, health professionals and politicians - A national Danish project. Health Policy 2012; 105: 65-70.

19. Bach Larsen M, Pilegaard Hansen R, Gilså Hansen D, et al. Secondary care intervals before and after the introduction of urgent referral guidelines for suspected cancer in Denmark: a comparative beforeafter study. BMC Health Serv Res 2013; 13: 348.

20. Hamilton W. Five misconceptions in cancer diagnosis. Br J Gen Pract 2009; 59: 441-447.

21. Cant P, Yu D. Impact of the ' 2 week wait' directive for suspected cancer on service provision in a symptomatic breast clinic. BJS Open 2000; 87: 1082-1086. 
22. Potter S, Govindarajulu S, Shere M, et al. Referral patterns, cancer diagnoses, and waiting times after introduction of two week wait rule for breast cancer: prospective cohort study. BMJ 2007; 335: 288.

23. Greene W. Econometric Analysis. 5th ed. Prentice Hall, Upper Saddle River, NJ, 2003.

24. Leamer E. Specification Searches: Ad Hoc Inference with Nonexperimental Data. John Wiley \& Sons, Hoboken, NJ, 1978.

25. Lin M, Cameron H, Shmueli G. Too Big to Fail: Large Samples and the p-Value Problem. Information Systems Research; 2013; 24:4: 906-917.

\section{Appendix 1}

Descriptive statistics for the middle period.

\begin{tabular}{|c|c|c|c|c|}
\hline & & \multicolumn{3}{|c|}{ Middle } \\
\hline \multicolumn{2}{|c|}{ Specialty } & Quantity & Mean (SD) & Median (Q1-Q3) \\
\hline \multicolumn{5}{|c|}{ Pathology } \\
\hline \multirow[t]{3}{*}{ Cyto } & Prio1 & 363 & 2.44 (1.89) & $1.9(1.0-3.9)$ \\
\hline & CCP & 304 & $3.07(2.60)$ & $2.2(1.1-4.8)$ \\
\hline & Prio2 & 3598 & 4.21 (3.47) & $3.2(1.9-5.8)$ \\
\hline \multirow[t]{3}{*}{ Histo } & CCP & 792 & $4.26(2.38)$ & $4.1(2.2-5.2)$ \\
\hline & Prio1 & 1548 & $5.72(4.20)$ & $4.9(2.8-7.1)$ \\
\hline & Prio2 & 18378 & $10.88(4.65)$ & 10.1 (7.8-13.1) \\
\hline \multicolumn{5}{|c|}{ Radiology } \\
\hline \multirow[t]{6}{*}{ Ст } & Prio1 & 8443 & $3.93(8.85)$ & $1.6(0.7-4.1)$ \\
\hline & Prio2 & 2248 & $6.51(12.81)$ & $3.1(1.1-7.8)$ \\
\hline & CCP & 486 & $6.85(6.02)$ & $5.1(2.9-8.6)$ \\
\hline & Prio3 & 1682 & 16.80 (21.65) & 14.1 (9.1-19.9) \\
\hline & Prio4 & 1440 & $39.70(23.42)$ & $35.1(22.0-53.0)$ \\
\hline & Prio5 & 504 & $48.32(32.00)$ & $41.5(25.1-64.3)$ \\
\hline \multirow[t]{6}{*}{ MR } & Prio1 & 562 & $6.13(7.77)$ & $3.2(1.2-8.0)$ \\
\hline & Prio2 & 1212 & $6.73(7.89)$ & $4.0(1.9-8.1)$ \\
\hline & CCP & 31 & 11.31 (9.64) & $9.2(7.0-12.3)$ \\
\hline & Prio3 & 863 & 17.70 (11.56) & $15.0(10.2-21.2)$ \\
\hline & Prio4 & 1801 & $63.53(40.32)$ & $57.9(41.5-77.0)$ \\
\hline & Prio5 & 914 & 89.52 (41.10) & $88.3(70.9-106.0)$ \\
\hline
\end{tabular}

\section{Acknowledgements}

The author would like to thank participants at Kalmar County Hospital. Special thanks to statistician Lars Brudin for necessary guidance and Johan Rosenqvist, Annkristin Svensbergh, Björn Forsberg and Vedran Azinovic for insightful comments on operations at the hospital. Associate Professor Erik Sandberg and Professor Mattias Elg at Linköping University are also thanked for comments on earlier versions of the paper. 